\title{
Risks of multiple sclerosis in relatives of patients in Flanders, Belgium
}

\author{
Herwig Carton, Robert Vlietinck, Jan Debruyne, Jacques De Keyser, \\ Marie-Beatrice D'Hooghe, Ruth Loos, Robert Medaer, Luc Truyen, Irene M L Yee, \\ A Dessa Sadovnick
}

Center for Human Genetics, University of Leuven

R Vlietinck

$\mathrm{R}$ Loos

Department of

Neurology, University

Hospital of Ghent

J Debruyne

Department of

Neurology, University

Hospital of VUB,

Brussels

J De Keyser

Department of

Neurology, University

Hospital of Antwerp

L Truyen

MS Center Melsbroek

M-B D'Hooghe

DWI Diepenbeek,

Belgium

R Medaer

Department of

Medical Genetics,

University of British

Columbia, Canada

I M L Yee

A D Sadovnick

Correspondence to:

Professor H Carton,

Department of Neurology,

Universitaire Ziekenhuizen,

B 3000 Leuven, Belgium.

Received 16 May 1996

and in final revised form

26 November 1996

Accepted 10 December 1996

(F Neurol Neurosurg Psychiatry 1997;62:329-333)

Keywords: multiple sclerosis; familial multiple sclerosis; recurrence risk

The aetiology of multiple sclerosis remains somewhat uncertain. Data on (a) family aggregation, (b) twins, (c) birth order position, (d) conjugal multiple sclerosis, $(e)$ year and age of onset among affected siblings, and $(f)$ ethnically resistant groups living in high risk areas for multiple sclerosis (for reviews see Sadovnick et $a l^{1}$ and Ebers and Sadovnick ${ }^{2}$ ) support the importance of genetic factors in the overall aetiology of multiple sclerosis. Most recently, studies of non-biological (adopted/adoptive) ${ }^{3}$ first degree relatives and half sibs ${ }^{4}$ of patients with multiple sclerosis clearly showed a genetic basis for the familial aggregation of multiple sclerosis. It now seems unlikely that the familial aggregation of multiple sclerosis results from any non-genetic factor such as a transmissible infectious agent as suggested by Kurtzke. ${ }^{5}$

The Flanders region of Belgium provides an excellent, and in some cases unique, opportunity to conduct a family study in multiple sclerosis for the following reasons: (1) Flanders is a

\begin{abstract}
Department of Neurology H Carton

Abstract

Objectives-To calculate age adjusted risks for multiple sclerosis in relatives of Flemish patients with multiple sclerosis. Methods-Lifetime risks were calculated using the maximum likelihood approach. Results-Vital information was obtained on 674 probands with multiple sclerosis in Flanders and a total of their 26225 first, second, and third degree relatives. Full medical information to allow documentation of multiple sclerosis status was available for $21351(81.4 \%)$ relatives. The age adjusted risk for parents was 1.61 (SEM $0 \cdot 35) \%$, for siblings $2 \cdot 10(\mathrm{SE} 0.36) \%$, and for children 1.71 (SEM 0.70)\%. For aunts and uncles, the risk was 0.66 (SEM 0.13)\%.

Conclusions-The risk for first degree relatives of patients with multiple sclerosis in Flanders is increased 10-fold to 12fold; for second degree relatives, it is increased threefold. This information can be used for risk counselling in families and provides additional support for the role of more than one locus contributing to the susceptibility of multiple sclerosis.
\end{abstract}

relatively homogeneous Dutch speaking area; (2) recent prevalence data are available for multiple sclerosis ${ }^{6}(88 / 100000$ population or $0.088 \%$ ); (3) the population of Flanders is not highly migratory with families tending to remain in contact much more regularly than is the situation in many other countries, such as Canada and the United States; (4) government records, accessible to researchers at the time of this study, are meticulously maintained and allow family pedigrees to be constructed for several generations, using the vital information on births and deaths, and (5) medical care in Flanders is essentially accessible to the entire population regardless of geographical location and socioeconomic status.

The present study was designed to assess the familial nature of multiple sclerosis using data on the Flemish population with multiple sclerosis. This is the first comprehensive family study of a large representative Dutch speaking population. It is also the first study of this kind on the European continent.

\section{Methods}

The study period was 1 October 1992 to 30 June 1994 inclusive.

\section{OVERALL ASCERTAINMENT}

Ascertainment was designed to be random in terms of case identification and family history of multiple sclerosis. Cases were ascertained as follows to ensure that the entire range of multiple sclerosis was included-that is, from benign cases to severely disabled patients. Probands were ascertained from: (1) the two multiple sclerosis clinics in Flanders-namely, the National Centre for Multiple Sclerosis at Melsbroek and the Multiple Sclerosis Clinic at Overpelt. Both centres largely see patients needing rehabilitation or long term care. At each centre, every second patient (proband) presenting during the study period was enrolled in the study. For each proband, vital data (age, sex) and basic medical information (diagnosis of multiple sclerosis, age at onset of multiple sclerosis, EDSS score, ${ }^{7}$ first symptoms, and multiple sclerosis course and duration) were available from the centre databases: (2) neurologists practising outside of the two multiple sclerosis clinics selected so that they covered all the subregions of Flanders. Neurologists were asked to participate in the study by enrolling every patient with multiple sclerosis seen as an "in hospital" or "office" patient during the study period. Cases were cross referenced for duplicate entry. 
DIAGNOSIS IN PROBANDS

To be included in the study, a proband had to have Belgian nationality and fulfill the criteria of Poser $e t a l^{8}$ for definite or probable multiple sclerosis. Each potential participating proband was examined to ensure that the Poser criteria were fulfilled and the EDSS score was determined. Vital and basic medical information (see above) were available for all probands.

\section{FAMILY STUDY PARTICIPATION}

Each ascertained proband was asked to participate in the family study by his or her multiple sclerosis clinic or private neurologist. The neurologist explained the aim of the study, clearly stating that a decision not to participate would in no way jeopardise future medical contacts. Probands who agreed to participate were contacted by telephone by one of the study's four field workers. Personal interviews were held as soon as possible, either at the neurologists' office or in the probands' home.

Using a structured and standardised interview, the field worker asked about the proband's family to obtain sufficient information to construct a first draft of the family pedigree. The field worker then augmented and verified the family information using government vital records. Thus for each proband, a complete pedigree (with respect to vital information) could be constructed for all first, second, and third degree relatives.

\section{MEDICAL FAMILY HISTORY}

Using a structured questionnaire, family members of the proband were contacted and asked questions about themselves and other family members to identify any "multiple sclerosis" in the relatives. Specifically, the informants were asked whether any person in the family had had (a) a diagnosis of multiple sclerosis; (b) problems with vision, gait, or balance; (c) a lumbar puncture, or (d) treatment with corticosteroids.

With appropriate consent, relevant medical or necropsy data were obtained for each reportedly affected family member. Whenever possible, the relatives were assessed by a study neurologist. If neither clinical documentation nor a clinical examination was possible, one of the five study neurologists (JD, JDK, MBD, RM, LT) discussed the case in detail with knowledgeable family informants. When doubt remained, a "best estimate" diagnosis of multiple sclerosis was then assigned by the study's senior neurologist (HC). Only relatives for whom HC had no doubt about the diagnosis of multiple sclerosis were included. If there was any uncertainty about the diagnosis, the relative was coded as "unaffected" for the purpose of this study. It is thus likely that the study may underestimate the number of affected relatives.

\section{TRAINING OF THE FIELD WORKERS}

Field workers were three nurses and one social worker experienced in working with patients with multiple sclerosis. The study's aim and methodology were taught as well as specific interview techniques. Each field worker was trained over several days using role playing methods. The study director (RV) met weekly with each field worker to monitor progress and to consider any urgent issues and concerns. Medical, demographic, and genetic information were discussed three times a month with the field workers, study neurologists, and epidemiologists (RL, RV). Decisions were made as necessary by the two principal investigators (HC, RV) who met monthly.

\section{ANALYSES}

For the Flanders data, the lifetime risks for relatives of probands to also develop multiple sclerosis were calculated using the maximum likelihood approach as described by Risch. ${ }^{9}$ This method assumes an age of onset distribution for relatives of probands based on an observed age of onset distribution, in the absence of accurate age of onset information for the relatives.

Relatives of probands with multiple sclerosis were obtained using cluster sampling (many relatives for each proband). Clustering was not considered in the calculation of standard errors (SEM) for the risk estimates and therefore the SEM presented may be lower than the true SEM. However, as very few probands in the present study had more than one affected relative, this effect would be negligible.

The $95 \%$ confidence intervals (95\% CIs) were computed using SEMs for some of the risk estimates. However, when the risk estimate was small and the affected relatives were fewer than 10 , calculating the $95 \%$ CI from the SEM would give only rough intervals.

Comparison of the Flemish and Canadian data was formally done using the $Z$ test. Canadian data used in these analyses were updated from Sadovnick et al. ${ }^{10}$

\section{Results}

PARTICIPANTS/NON-PARTICIPANTS

A total of 831 probands were ascertained. Three hundred and sixty six (44\%) were recruited from the two major multiple sclerosis clinics (Melsbroek $\mathbf{n}=230$; Overpelt $\mathbf{n}=$ 136). The remaining $465(56 \%)$ were recruited through 58 neurologists covering every subregion of Flanders (west Flanders, $n$ = 133; Antwerp, $\mathrm{n}=106$; east Flanders, $\mathrm{n}=$ 103; Limburg, $n=72$; Flemish half of Brabant, $n=51$ ). Of the 831 probands, seven $(0 \cdot 8 \%)$ refused to participate. The remaining 824 were all contacted by a field worker. Eleven probands were subsequently excluded from the study because the nationality was found not to be Belgian. During the course of the study, 55 probands withdrew for the following reasons: (a) the proband was too ill to communicate and other family informants were unavailable $(\mathrm{n}=11)$; $(b)$ the proband died ( $n=8)$; (c) the family did not wish to cooperate $(\mathrm{n}=17)$; or $(d)$ the proband had lost contact with the family or a family feud interfered with documentation $(\mathrm{n}=19)$. Eighty four additional probands withdrew for non-specific reasons such as lack of ongoing interest, time restraints, etc. 
Table 1 Comparison of characteristics of the probands who withdrew during the study and those who stayed

\begin{tabular}{llll}
\hline & $\begin{array}{l}\text { Withdrew during } \\
\text { the study }\end{array}$ & Study probands & P value \\
\hline No of probands & 139 & 674 & - \\
Sex ratio F/M & $1.60: 1$ & $1.51: 1$ & $>0.05$ \\
Mean age (SD) & $49.7(11.3)$ & $47.6(11.8)$ & $>0.05$ \\
Mean age at onset (SD) & $32.9(9)$ & $32.6(9.8)$ & $>0.05$ \\
Mean duration of multiple sclerosis (SD) & $15.9(9.5)$ & $15.0(9.7)$ & $>0.05$ \\
Mean EDSS at last visit & $5.9(2.2)$ & $5.4(2.4)$ & $>0.05$ \\
Multiple sclerosis type: & 83.8 & 79.3 & $>0.05$ \\
RR and SP (\%) & 16.1 & 20.7 & \\
PP (\%) & & & \\
\hline
\end{tabular}

$\mathrm{RR}=$ Relapsing remitting; $\mathrm{SP}=$ secondary progressive; $\mathrm{PP}=$ primary progressive type of multiple sclerosis.

Table 2 Crude risks of having multiple sclerosis

\begin{tabular}{llll}
\hline Relation & No & Risk (\%) & SEM (\%) \\
\hline Parents & $21 / 1323$ & 1.59 & 0.34 \\
Full Sibs & $33 / 1836$ & 1.80 & 0.31 \\
Half Sibs & $1 / 60$ & 1.67 & 1.65 \\
Children & $6 / 994$ & 0.60 & 0.25 \\
Full aunts and uncles & $26 / 4071$ & 0.64 & 0.12 \\
Half aunts and uncles & $0 / 166$ & $0 \cdot 15$ & 0.07 \\
Nieces and nephews & $5 / 3261$ & 1.15 & $1 \cdot 14$ \\
Half nieces and nephews & $1 / 87$ & 0.37 & 0.06 \\
First cousins & $35 / 9553$ & & \\
\hline
\end{tabular}

Table 1 shows that the 674 participants were representative of the 139 non-participants.

The 674 study probands had a total of 26 225 first, second, and third degree relatives. The median number was 52 per pedigree, ranging between three and 195. Of these, there were 4389 first degree relatives, 9140 second degree relatives, and 12696 third degree relatives. Through government records, vital information was available for all these subjects.

AVAILABILITY OF RELIABLE MEDICAL

INFORMATION

Full medical information to allow documentation of multiple sclerosis status was available for 21351 of $26225(81 \cdot 4 \%)$ relatives. These included 4153 of $4389(94.6 \%)$ first degree relatives, 7392 of $9140(80.9 \%)$ second degree relatives, and 9806 of $12696(77 \cdot 2 \%)$ third degree relatives. The median number of persons with full medical information per family was 45; with vital information it was 52 . Full medical information was thus available for $81.4 \%$ of the relatives with the highest per- centage being for first degree relatives $(94 \cdot 6 \%)$. Four hundred and six $(60 \cdot 2 \%)$ of the 674 probands were female for a female : male ratio of $1.51: 1$. Of the 21351 relatives with full medical information, $12831(60 \cdot 1 \%)$ were relatives of female probands. A total of 128 affected relatives were identified, of whom 78 $(60.9 \%)$ were relatives of female probands. Thus the study group did not have an unexpected overrepresentation of female probands or underrepresentation of relatives of male probands.

\section{FAMILY STRUCTURE}

One hundred and four probands $(15 \cdot 4 \%)$ had at least one additional affected relative in the pedigree. Of these probands, $85(12.6 \%)$ had one affected relative, $14(2 \cdot 1 \%)$ had two affected relatives, and five $(0.7 \%)$ had three affected relatives. Although four pedigrees were linked, the analyses were based on independent ascertainment.

The median number of persons with full medical information was 53 in families with either one additional affected relative (range 6-105) or two additional affected relatives (range 11-107). In families with three additional affected relatives, the median number was 82 (27-109).

Eighty one of the $128(63.3 \%)$ affected relatives were female, with 49 of $81(60.5 \%)$ belonging to a pedigree with a female proband. The five families with three affected relatives each had a female proband. Nine probands were twins, with one monozygotic male pair being concordant for multiple sclerosis.

There were 27 parent-child pairs concordant for multiple sclerosis of which 15 $(55 \cdot 6 \%)$ were maternal and 12 were paternal. There were 11 mother-daughter pairs, four mother-son pairs, six father-daughter pairs, and six father-son pairs.

CRUDE RISKS OF HAVING MULTIPLE SCLEROSIS One hundred and twenty eight ( 81 females, 47 males) or $0.57 \%$ of the 21351 relatives on whom full medical information was available had documented multiple sclerosis. Crude risks were calculated from the number of rela-

Table 3 Age adjusted risks of multiple sclerosis for first, second, and third degree relatives by sex of probands

\begin{tabular}{|c|c|c|c|c|c|c|}
\hline \multirow{3}{*}{$\begin{array}{l}\text { Relationship to } \\
\text { proband }\end{array}$} & \multicolumn{6}{|l|}{ Proband } \\
\hline & \multicolumn{2}{|l|}{ Female } & \multicolumn{2}{|l|}{ Male } & \multicolumn{2}{|c|}{ Total males and females* } \\
\hline & No & Risk (SEM)\% & No & Risk (SEM)\% & No & Risk (SEM)\% \\
\hline $\begin{array}{l}\text { Mother } \\
\text { Father } \\
\text { Sister } \\
\text { Brother }\end{array}$ & $\begin{array}{l}7 / 402 \\
5 / 395 \\
9 / 525 \\
7 / 567\end{array}$ & $\begin{array}{l}1.76(0.66) \\
1.28(0.57) \\
2.00(0.66) \\
1.44(0.54)\end{array}$ & $\begin{array}{r}4 / 261 \\
5 / 265 \\
12 / 366 \\
5 / 378\end{array}$ & $\begin{array}{l}1.55(0.77) \\
1.92(0.85) \\
3.81(1.08) \\
1.55(0.69)\end{array}$ & $\begin{array}{l}11 / 663 \\
10 / 660 \\
21 / 891 \\
12 / 945\end{array}$ & $\begin{array}{l}1.68(0.50) \\
1.53(0.48) \\
2.74(0.59) \\
1.48(0.43)\end{array}$ \\
\hline $\begin{array}{l}\text { Parents } \\
\text { Siblings } \\
\text { Children }\end{array}$ & $\begin{array}{c}12 / 797 \\
16 / 1092 \\
4 / 594\end{array}$ & $\begin{array}{l}1.52(0.44) \\
1.71(0.42) \\
1.87(0.93)\end{array}$ & $\begin{array}{r}9 / 526 \\
17 / 744 \\
2 / 400\end{array}$ & $\begin{array}{l}1.73(0.57) \\
2.67(0.64) \\
1.51(1.06)\end{array}$ & $\begin{array}{c}21 / 1323 \\
33 / 1836 \\
6 / 994\end{array}$ & $\begin{array}{l}1.61(0.35) \\
2.10(0.36) \\
1.73(0.70)\end{array}$ \\
\hline $\begin{array}{l}\text { Aunts } \\
\text { Uncles } \\
\text { Female first cousins } \\
\text { Male first cousins } \\
\text { Nieces } \\
\text { Nephews }\end{array}$ & $\begin{array}{c}16 / 1270 \\
6 / 1209 \\
10 / 2924 \\
8 / 2949 \\
2 / 898 \\
3 / 965\end{array}$ & $\begin{array}{l}1.29(0.32) \\
0.51(0.21) \\
0.41(0.13) \\
0.33(0.12) \\
0.65(0.46) \\
0.94(0.54)\end{array}$ & $\begin{array}{c}2 / 804 \\
2 / 788 \\
12 / 1866 \\
5 / 1814 \\
0 / 709 \\
0 / 689\end{array}$ & $\begin{array}{l}0.25(0 \cdot 18) \\
0.26(0 \cdot 18) \\
0.75(0 \cdot 22) \\
0.33(0 \cdot 15) \\
0- \\
0-\end{array}$ & $\begin{array}{r}18 / 2074 \\
8 / 1997 \\
22 / 4790 \\
13 / 4763 \\
2 / 1607 \\
3 / 1654\end{array}$ & $\begin{array}{l}0.89(0.21) \\
0.41(0.15) \\
0.54(0.11) \\
0.33(0.09) \\
0.36(0.25) \\
0.54(0.31)\end{array}$ \\
\hline $\begin{array}{l}\text { Aunts/uncles } \\
\text { First cousins } \\
\text { Nieces/nephews }\end{array}$ & $\begin{array}{r}22 / 2479 \\
18 / 5873 \\
5 / 1863\end{array}$ & $\begin{array}{l}0.91(0.19) \\
0.37(0.09) \\
0.80(0.36)\end{array}$ & $\begin{array}{r}4 / 1592 \\
17 / 3680 \\
0 / 1398\end{array}$ & $\begin{array}{l}0.26(0.13) \\
0.54(0.13) \\
0\end{array}$ & $\begin{array}{r}26 / 4071 \\
35 / 9553 \\
5 / 3261\end{array}$ & $\begin{array}{l}0.66(0.13) \\
0.44(0.07) \\
0.45(0.20)\end{array}$ \\
\hline
\end{tabular}

^Excludes half relatives. 
Table 4 Comparison of age adjusted risk of multiple sclerosis for kinships

\begin{tabular}{lllll}
\hline Relationship to proband & $\begin{array}{l}\text { Proportion of } \\
\text { genes shared }\end{array}$ & $\begin{array}{l}\text { Mean age } \\
\text { or age at death }\end{array}$ & Risk & Ratio \\
\hline Aunts/uncles $v$ parents & 0.50 & $69.9 v 69.7$ & $0.66 v 1.68$ & 0.39 \\
First cousins $v$ sibs & 0.25 & $47.9 v 48.0$ & $0.44 v 2.10$ & $0 \cdot 21$ \\
Nieces/nephews $v$ children & 0.25 & $23.7 v 23.7$ & $0.45 v 1.73$ & 0.26 \\
\hline
\end{tabular}
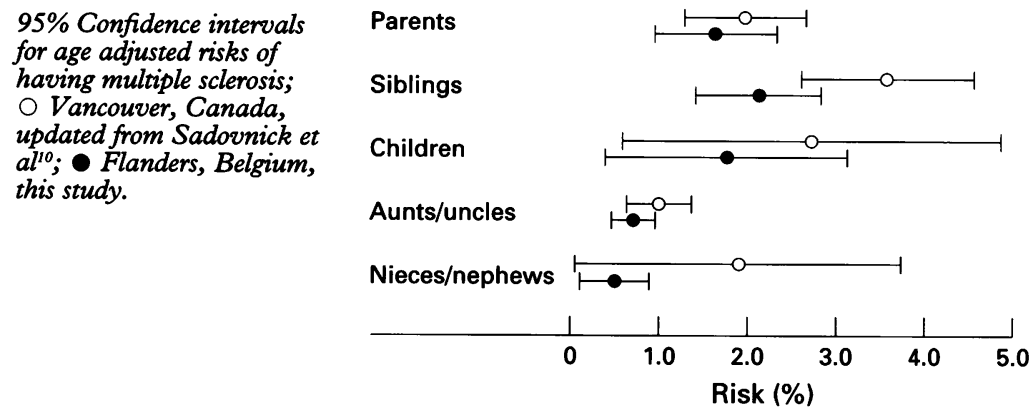

tives with full medical information as the denominator, excluding those with only vital information.

Table 2 gives the crude risks: $1 \cdot 44 \%$ of the first degree, $0.41 \%$ of the second degree, and $0.37 \%$ of the third degree had documented multiple sclerosis.

\section{AGE ADJUSTED RISKS OF HAVING MULTIPLE SCLEROSIS}

For all categories of relatives, age adjusted risks were calculated. Age adjusted risks take into account the age structure of the study population and the age of onset distribution for affected members. Only those relatives with known sex, age at present, or death at age, and multiple sclerosis status were included. Table 3 gives the age adjusted risks for relatives by sex of the proband and for all probands. The risks were estimated for all children as a group instead of daughters and sons separately because of their small numbers. Half sibs (one affected), half niece/ nephews (one affected), and half aunts/uncles (none affected) were excluded from these calculations.

COMPARISON OF RISKS OF HAVING MULTIPLE SCLEROSIS FOR DIFFERENT KINSHIPS

Because age, the time period when the diagnosis of multiple sclerosis was made, and the proportion of deceased relatives may all affect the documentation of multiple sclerosis and thus the risks, comparison of risks by cohort is appropriate. Table 4 gives a comparison of the risks for different kinships separated into birth cohorts. The risk is consistently higher for first degree relatives of probands.

Table 5 Comparison of the age adjusted risks between Flanders and Vancouver, by $Z$ test

\begin{tabular}{llll}
\hline & \multicolumn{2}{l}{ Age corrected risks for multiple sclerosis } \\
\cline { 2 - 4 } Category of Relative & Vancouver & Flanders & $Z$ score \\
\hline Parents & 0.0194 & 0.0161 & 0.6667 \\
Siblings & 0.0356 & 0.021 & $2.3697^{\star}$ \\
Children & 0.0269 & 0.0173 & 0.7408 \\
Aunts/uncles & 0.0096 & 0.0066 & 1.3031 \\
Nieces/nephews & 0.0185 & 0.0045 & 1.4568 \\
First cousins & 0.0204 & 0.0044 & $2.3406^{\star}$ \\
\hline${ }^{*}<0.01$. & & &
\end{tabular}

COMPARISON OF AGE ADJUSTED RISKS FOR FLANDERS AND CANADA

The figure compares age adjusted risks (95\% CIs) for first and second degree relatives of probands with multiple sclerosis in Flanders and Canada. All the $95 \%$ CIs overlap.

Flemish and Canadian data were compared using the $\mathrm{Z}$ test. Although the risks with $95 \%$ CIs all overlapped (figure), specific analyses showed that these risks were significantly different for sibs $(Z=2.3697 ; P<0.01$; table 5$)$.

\section{Discussion}

This study is a comprehensive estimate of risks of multiple sclerosis in first, second, and third degree relatives of Flemish probands with multiple sclerosis.

The only other published comprehensive study of age adjusted familial risks at the time the Flemish study was designed and executed was the Canadian study. ${ }^{10}$ The Canadian study group consisted of 815 probands and 11 345 of their first, second, and third degree relatives. Very recently a report on age adjusted recurrence risks for relatives of patients with multiple sclerosis in Cambridgeshire, United Kingdom, was published. ${ }^{11}$

The Flemish study differed from the Canadian study as follows: (1) The Flemish study population is very homogeneous; $96 \%$ are descendants of the 2500000 inhabitants of Flanders in 1830 (Belgian National Institute of Statistiek). The Canadian study population consisted of white people of northern and central European ancestry, with the majority being of United Kingdom ancestry; (2) government vital data were available in Belgium but not in Canada thereby ensuring more accurate numerators and denominators for the Flemish pedigrees, and (3) the Canadian population is very migratory-especially important as the degree of the relation to the proband increases and family contacts diminish.

The figure gives the age adjusted risks with 95\% CIs for parents, siblings, children, aunts/uncles and nieces/nephews in Flanders and Canada. Data are most complete for first degree relatives and this is reflected in the figure by the similar $95 \%$ CIs for the two study groups. For the more distant relations, the 95\% CIs are much wider for the Canadian data because, as discussed previously, less information is available for more distant relatives (data not presented). The risks do not overlap for third degree relatives (first cousins). This is thought to be artifactual, reflecting the difficulty in accurately extending the Canadian pedigrees to third degree relatives in the absence of any vital records.

The overall sib risk for the Flemish population $(2 \cdot 1(95 \%$ CI $1 \cdot 38-2 \cdot 82) \%)$ is significantly lower than that for the Canadian population $(3.6(95 \%$ CI $2 \cdot 6-4 \cdot 6) \%)$. The Canadian sib rate reflects that for the United Kingdom $^{11}$ (3.82 (95\% CI $\left.\left.2 \cdot 77-5 \cdot 15\right) \%\right)$. As previously stated, the Canadian study population largely consists of white families with United Kingdom ancestry. Thus the ethnic 
make up of the Flemish population differs from Canada and the United Kingdom, a possible factor in sib risks. Recent data from Canada $^{13}$ suggest that age of onset of multiple sclerosis for the proband is an important covariate for calculating multiple sclerosis sib risks, with risks increasing as age of onset decreases. It may therefore be important to note that the mean age of onset of multiple sclerosis for Canadian probands is 30.3 (SD $9 \cdot 7)$ years, significantly younger $(Z=4 \cdot 52$, $P<0.01)$ than the mean age of onset for the Flemish data (32.6 (SD 9.8) years).

In Flanders, the risk for first degree relatives approaches $1.9 \%$ compared with a population frequency of 0.088 (95\% CI $0.076-0.099) \%$. The lifetime risk can be estimated to be double this rate or roughly $0 \cdot 175 \% .{ }^{6}$ Thus the recurrence risk for first degree relatives of multiple sclerosis probands in Flanders represents a 10-fold to 12-fold increase (table 3). For a member with an affected second degree relative in Flanders, the lifetime risk is increased threefold. This increased risk for first degree relatives (or familial aggregation) is most probably entirely due to genetic factors, as has been convincingly shown recently in studies of adopted or adoptive relatives ${ }^{3}$ and half $\operatorname{sibs}^{4}$ in Canada.

The comparison of risks in kinships sharing $50 \%$ or $25 \%$ of the genes does not support the implication of a single susceptibility gene inherited according to Mendelian autosomal or recessive models. The results rather support an multigenetic model as already indicated by the difference in concordance rates found amongst monozygotic (25\%-30\%) and dizygotic twins $(3 \%-4 \%){ }^{14} 15$

In summary, results of this comprehensive Flemish study can be used for risk counselling in Flemish families with multiple sclerosis and provide additional support for the role of more than one locus contributing to the susceptibility of multiple sclerosis.

We thank Dr Wim Meulemans (geneticist); Alex De Waele, Kathleen Gysen, Lea Mertens, Iris Smouts (field workers); Kaat Kathleen Gysen, Lea Mertens, Iris Smouts (field workers); Kaat Binon (administrative coordinator); and Luc Van de Gaer (neu-
rologist). We also thank the collaborating neurologists who provided patients and information.

This study was supported by a grant of the Nationaal Fonds voor Wetenschappelijk Onderzoek (NFWO), the VZW Wetenschappelijk Onderzoek Multiple Sclerose (WOMS), and a Collaborative Research Grant of the NATO.

Calculation of the updated Canadian recurrence risk data was done as part of the Canadian Collaborative Project on Genetic Susceptibility to multiple sclerosis, funded by the Multiple Susceptibility to multiple sclerosis, funded by the Multiple the Multiple Sclerosis Society of Canada. We thank Dr G Ebers, University of Western Ontario, for helpful comments.

1 Sadovnick AD, Ebers GC. Epidemiology of multiple sclerosis: a critical overview. Can $\mathcal{F}$ Neurol Sci 1993;20:7-29.

2 Ebers GC, Sadovnick AD. The role of genetic factors in multiple sclerosis susceptibility: a critical review. $f$ multiple sclerosis susceptibility:

3 Ebers GC, Sadovnick AD, Risch NJ, et al. Genetic basis for the familial aggregation in multiple sclerosis. Nature 1995; 377:150-1.

4 Sadovnick AD, Ebers GC, Dyment DA, et al. Evidence for the genetic basis of multiple sclerosis. The Lancet 1996; 347:1728-30.

5 Kurtzke JF. Epidemiologic evidence for multiple sclerosis as an infection. Clin Microbiol Rev 1993;6:382-427.

6 Van Ooteghem P, D'Hooghe MB, Vlietinck R, Carton $H$. Prevalence of multiple sclerosis in Flanders, Belgium. Neuroepidemiology 1994;13:220-5.

7 Kurtzke JF. Rating neurologic impairment in multiple sclerosis: an expanded disability status scale (EDSS). Neurology 1983;33:1444-52.

8 Poser CM, Paty DW, Scheinberg L. et al. New diagnostic criteria for multiple sclerosis. Guidelines for research protocols. Ann Neurol 1983;13:227-31.

9 Risch N. Estimating recurrence risks with variable age of onset: review of methods and a maximum likelihood approach. Biometrics 1983;39:929-39.

10 Sadovnick AD, Baird PA, Ward RH. Multiple sclerosis: updated risks. $A m \mathcal{F}$ Med Genet 1988;29:533-41.

11 Robertsen NM, Fraser M, Deans J, Clayton D, Walker N, Compston DAS. Age-adjusted recurrence risks for relatives of patients with multiple sclerosis. Brain 1996;119: 449-55.

12 Sweeney VP, Sadovnick AD, Brandejs V. Prevalence of multiple sclerosis in British Columbia. Can 7 Neurol Sci 1986;13:47-51.

13 Sadovnick AD, Ebers GC, Risch NJ and the Canadian Collaborative Study Group. Sib risks for multiple sclerosis [abstract]. Neurology 1996;46:A335-6.

14 Ebers GC, Bulman DE, Sadvnick AD, et al. A populationbased study of multiple sclerosis in twins. $N$ Engl $f$ Med 1986;315:1638-42

15 Mumford CJ, Wood NW, Kellar-Wood H, et al. The British Isles survey of multiple sclerosis in twins. Neurology 1994; 44:11-15 